\title{
Cutaneous Lichtenberg figures from lightning strike
}

\author{
Eric Mutter MD, Annie Langley MD MSc
}

- Cite as: CMAJ 2019 March 4;191:E260. doi: 10.1503/cmaj.181221

$\mathbf{T}$

wo young adults were examined in a Northern Ontario hospital after sustaining indirect lightning injuries while camping. The patients were laying on their left sides in a tent during a storm and encountered a transfer of electricity from a lightning strike to a nearby tree. They did not lose consciousness, but both reported having had a few seconds of paralysis followed by paresthesias for 1-2 hours. They called emergency services, and paramedics found them in their tent; both were conscious and had normal vital signs.

A complete physical examination by the emergency physician was unremarkable other than unusual skin lesions resembling ferns on their left flanks (in contact with the ground during the lightening strike; Figure 1). Results from electrocardiograms and bloodwork were normal, with no evidence of organ damage. After 6 hours of uneventful cardiac monitoring, the patients were discharged in stable condition but with persistent skin lesions.

Lichtenberg figures are nonburn skin injuries that are pathognomonic for lightning exposure. These figures were first described by Georg Christoph Lichtenberg in 1777 and are a useful diagnostic tool for injury caused by lightning because patients frequently present unconscious or unable to recall a history of lightning strike. ${ }^{1}$ Other clues suggestive of lightning injury include arrhythmias and rhabdomyolysis. The pathophysiology of Lichtenberg figures is unknown but may involve damage and leakage from cutaneous blood vessels owing to transmission of electrical current through the skin. ${ }^{1}$ Lesions are asymptomatic and appear within an hour of exposure on moist skin (which can conduct electrical current), and last up to 48 hours. No treatment is required because these lesions are not burns; however, physicians should be aware of the possibility of concomitant thermal burns that may require intervention. ${ }^{1}$

\section{Reference}

1. Ritenour AE, Morton MJ, McManus JG, et al. Lightning injury: a review. Burns 2008;34:585-94.

\section{Competing interests: None declared.}

This article has been peer reviewed.

The authors have obtained patient consent.

Affiliations: Department of Emergency Medicine (Mutter) and Division of Dermatology (Langley), The Ottawa Hospital, Ottawa, Ont.

Correspondence to: Annie Langley, alangley@toh.ca

Clinical images are chosen because they are particularly intriguing, classic or dramatic. Submissions of clear, appropriately labelled highresolution images must be accompanied by a figure caption. A brief explanation (300 words maximum) of the educational importance of the images with minimal references is required. The patient's written consent for publication must be obtained before submission. 